\title{
A Qualitative Assessment of Patient Satisfaction with Radical Cystectomy for Bladder Cancer at a Single Institution: How Can We Improve?
}

This article was published in the following Dove Press journal: Research and Reports in Urology

\author{
Lukas Hockman' \\ Jacob Bailey' \\ Jacob Sanders' \\ Catherine Muzzey' \\ Mark Wakefield (D' \\ Amy Christensen ${ }^{2}$ \\ Katie Murray (D) \\ 'Division of Urology, Department of \\ Surgery, School of Medicine, University of \\ Missouri, Columbia, Missouri, USA; \\ ${ }^{2}$ Department of Health Management and \\ Informatics, University of Missouri, \\ Columbia, Missouri, USA
}

Purpose: To evaluate patient satisfaction (with emphasis on preoperative education) with radical cystectomy for bladder cancer at our institution, the University of Missouri Hospital, qualitatively in order to identify specific areas where improvements can be made.

Materials and Methods: We developed a patient survey that used open-ended questions to identify positive and negative experiences that contributed to patient satisfaction. We administered the survey to radical cystectomy patients who met inclusion criteria and agreed to participate. We recorded, transcribed and qualitatively coded the responses. We identified four themes under which both positive and negative responses were placed, and constructed two diagrams to better illustrate contributors to patient experience and satisfaction.

Results: We identified 25 patients who met inclusion criteria. Of those, 13 participated in the survey. Regarding overall experience, $92.3 \%$ of patients rated their care as excellent or good. Regarding preoperative education, $76.9 \%$ of patients reported they definitely or somewhat received enough information on what to expect after surgery, and $76.9 \%$ definitely received enough guidance on how to care for themselves after surgery. From qualitative coding of patient responses to open-ended questions, we identified preoperative preparation, delivery of care, caregiver availability, and patient-centered care as themes that contributed positively and negatively to patient experience.

Conclusion: Although the overall patient satisfaction could be perceived as high $(92.3 \%)$, qualitative analysis revealed several areas where improvements can be made to improve patient experience with radical cystectomy at our institution. As previously expected, preoperative preparation was a contributor.

Keywords: cystectomy, patient satisfaction, patient education, bladder cancer

\section{Introduction}

Over the past several decades there has been a shift in the paradigm of health-care quality. Historically, health-care quality was based largely on clinical outcomes such as complication rate or number or readmissions. More modern quality metrics focus on patient satisfaction. ${ }^{1}$ Evaluation of patient satisfaction within a health-care system is important as high patient satisfaction not only affects patients' decision to choose a health-care provider but also impacts their compliance with recommended treatment. ${ }^{2,3}$

In regard to surgical patients specifically, patient satisfaction is more controversial and less studied than health care as a whole. However, it is still an important component of quality surgical care. ${ }^{4}$ With this in mind, our institution recently implemented an enhanced recovery protocol for patients undergoing radical
Correspondence: Katie Murray

$\mathrm{Tel}+\mid$ 573-882-|| 5 |

Fax + I 573-884-7453

Email Murraykat@health.missouri.edu 
cystectomy $(\mathrm{RC})$ with a goal of improving patient satisfaction as well as overall outcomes. $\mathrm{RC}$ is the recommended treatment for patients with muscle invasive bladder cancer and certain patients with non-muscle invasive bladder cancer who fail initial therapy. ${ }^{5,6}$ Despite being the standard of care, $\mathrm{RC}$ is associated with significant morbidity and mortality, and has the highest complication rate, longest length of hospital stay, most readmissions and highest death rate among all urological procedures. ${ }^{7-9}$ Understandably, maintaining high patient satisfaction after $\mathrm{RC}$ is a challenge.

We therefore developed a study to evaluate contributors to patient satisfaction specific to RC for bladder cancer. The objective was to gather data on patient experience during the pre and perioperative period, with emphasis on preoperative education and preparation. We decided a qualitative, open-ended survey would provide the most meaningful information, and provide guidance on how to improve patient satisfaction with $\mathrm{RC}$ at our institution.

\section{Materials and Methods}

After obtaining exempt Institutional Review Board approval under exemption $46.104 \mathrm{~d} 2 \mathrm{i}$ for quality improvement at the University of Missouri Hospital, a survey was developed with assistance from a multi-disciplinary team including urological oncologists, patient satisfaction experts within the University of Missouri hospital, and nursing staff. The survey consisted of five questions regarding patient experience of undergoing $\mathrm{RC}$ for bladder cancer and addressed patient perspective on preoperative preparation and overall experience. Verbal consent was obtained with IRB approval and acceptance prior to delivering the questions. The contacted patients were informed of our intentions of studying patient satisfaction and the goals of our study prior to providing consent. The following five questions were verbally asked to patients over the phone.

1. In regard to undergoing bladder removal surgery, as best as you can remember, would you describe your care as excellent, good, or fair?

2. What specifically do you remember about your care and service?

3. Did you receive enough information about what to expect after the surgery?

4. Did you receive enough guidance on how to care for yourself after the surgery?
5. What is one thing we could do to improve our care for patients who undergo a radical cystectomy in the future?

Patients who had undergone RC for bladder cancer in the previous three years at the University of Missouri were identified using billing data. All patients who were alive continued to follow up at the University of Missouri and had accurate contact information were deemed eligible for inclusion in this qualitative study. Unbiased fellows from the University of Missouri Masters of Health Administration program made evening telephone calls to included patients. The five questions above were asked to each patient who could be contacted and agreed to participate. All telephone conversations were recorded and transcribed. The responses were then qualitatively coded. Major themes were identified and responses were coded appropriately into those areas. Diagrams were then constructed using the coded responses to better illustrate contributing factors to the patients' overall experience with $\mathrm{RC}$ for bladder cancer at our institution.

\section{Results}

Over the past three years, 74 patients underwent $\mathrm{RC}$ for bladder cancer at the University of Missouri Hospital. At the time of this study, 25 patients remained alive and had accurate contact information. Of those, 13 patients answered the phone on the evening in which calls were made. All 13 patients agreed to participate in the survey (Figure 1). Participants age ranged from 57 to 88 , and $84 \%$ were male.

Of the five questions asked, three allowed for quantitative answers. Results of these questions are shown in Figure 2. The majority of the patients described their overall care as excellent or good with only one patient $(7.7 \%)$ describing their overall care as "fair". Most patients felt they received enough preoperative information in regard to their surgery, but three patients $(23.1 \%)$ answered "no", in that they did not receive enough preoperative information. Three patients $(23.1 \%)$ also felt they did not receive enough guidance on how to care for themselves after surgery.

The remaining two questions allowed for qualitative answers. The goal was to gain more information on the specifics that influenced patient responses to the quantitative answers and identify areas for improvement. The qualitative answers were coded into four themes that encompassed patient experiences. These themes were 


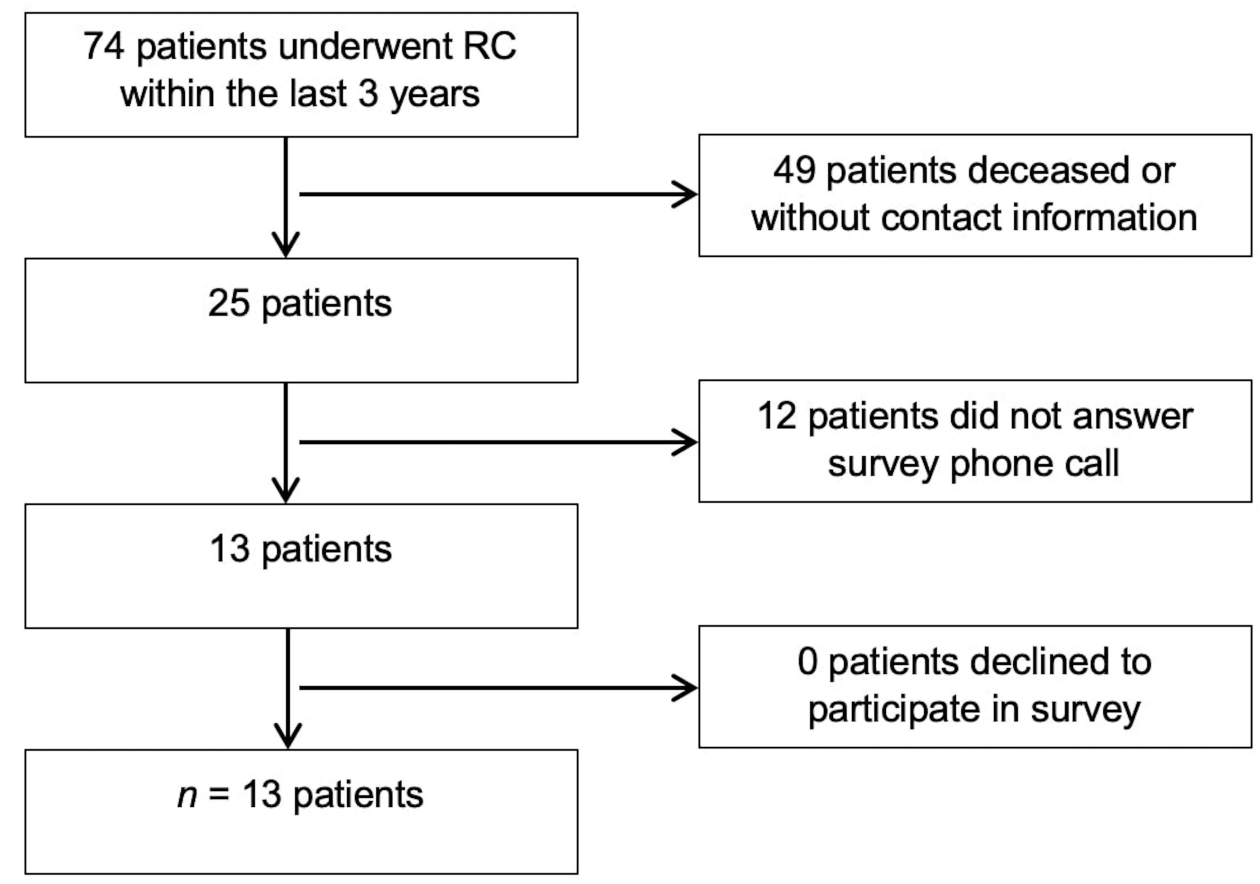

Figure I Flowchart of patients included and excluded from the study cohort.

Question

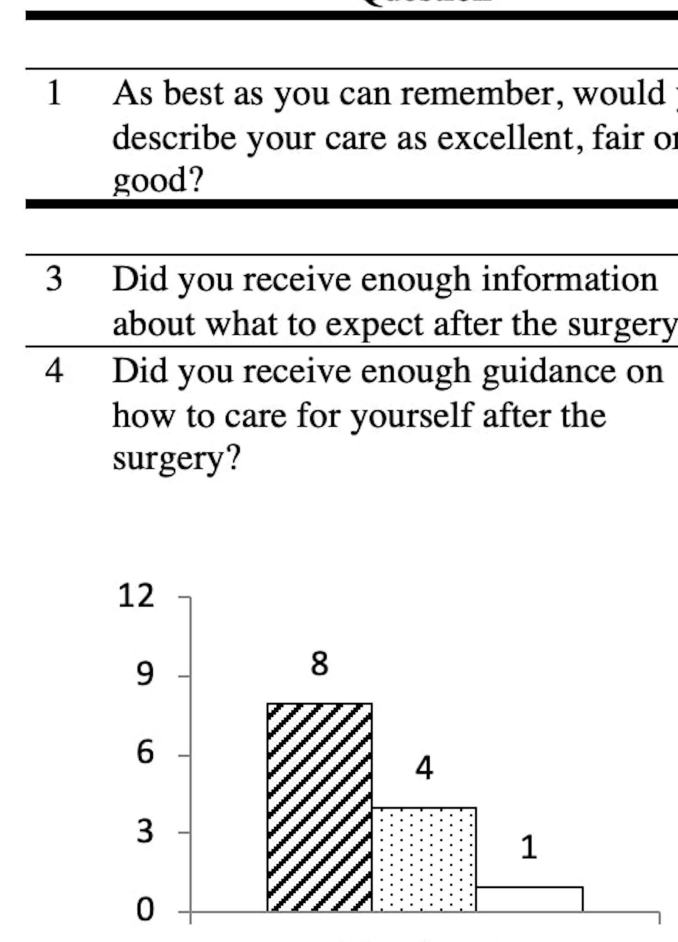

Question 1

$\square$ Excellent $\boxminus$ Good $\square$ Fair
Answer

Excellent

Good

Fair

$8(61.5 \%)$

$4(30.8 \%)$

$1(7.7 \%)$
No

$3(23.1 \%)$

$7(53.8 \%)$

$10(76.9 \%)$

$0(0 \%)$

$3(23.1 \%)$

$\begin{array}{ll}3(23.1 \%) & 3(23.1 \%) \\ 0(0 \%) & 3(23.1 \%)\end{array}$

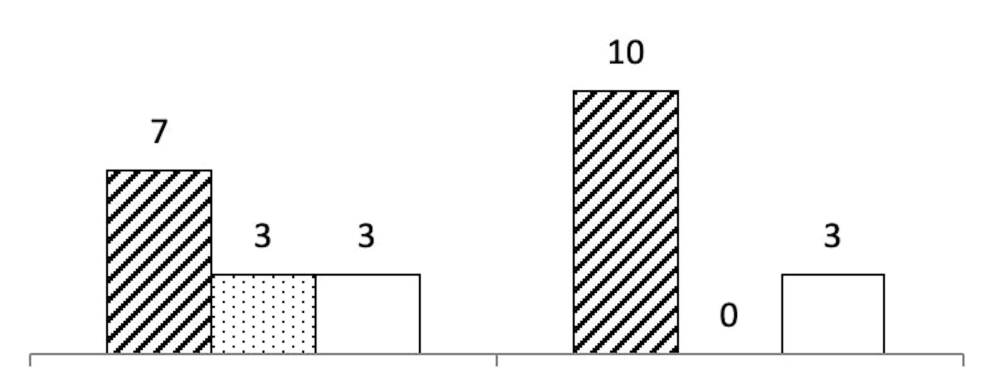

Question 3

Question 4

$\square$ Yes, definitely $\boxminus$ Yes, somewhat $\square$ No

Figure 2 Patient responses to quantitative survey questions. 
preoperative preparation, delivery of care, caregiver availability, and patient-centered care. Both positive and negative responses were coded in relation to these four themes, and are shown in Figures 3 and 4, respectively.

\section{Discussion}

Patient satisfaction is an integral part of quality health care. It has become important for health-care systems to continuously evaluate and understand contributors to patient satisfaction. Several previous studies have attempted to identify contributors to patient satisfaction specific to RC. Most of the published literature uses postoperative quality of life (QOL) as an indicator of patient satisfaction. ${ }^{10-13}$ Hospital recovery, postoperative rehabilitation and management of urinary diversion are also common areas of investigation. ${ }^{10,11,13-15}$ Most of these studies use generic, quantitative questionnaires that provide easily analyzed results, but can restrict the range of patient responses. ${ }^{16,17}$ Cerruto et al employed a narrative-based approach where interviews were conducted with RC patients to generate specific rather than generic contributors to postoperative QOL. ${ }^{18}$ From non-urological literature, Consuegra-Sanchez et al proposed "associative mapping" in which an aggregate map composed of individual responses to an open-ended survey was used to better illustrate larger themes that contributed to patient satisfaction in cardiology patients. ${ }^{19}$

In our study, we focused on patient experiences during the pre and perioperative period with less emphasis on long-term QOL measures. We employed a single generic question to provide a very basic assessment of overall patient satisfaction. A large majority (92.3\%) of patients thought their care was "excellent" or "good," which may indicate a high rate of overall patient satisfaction.

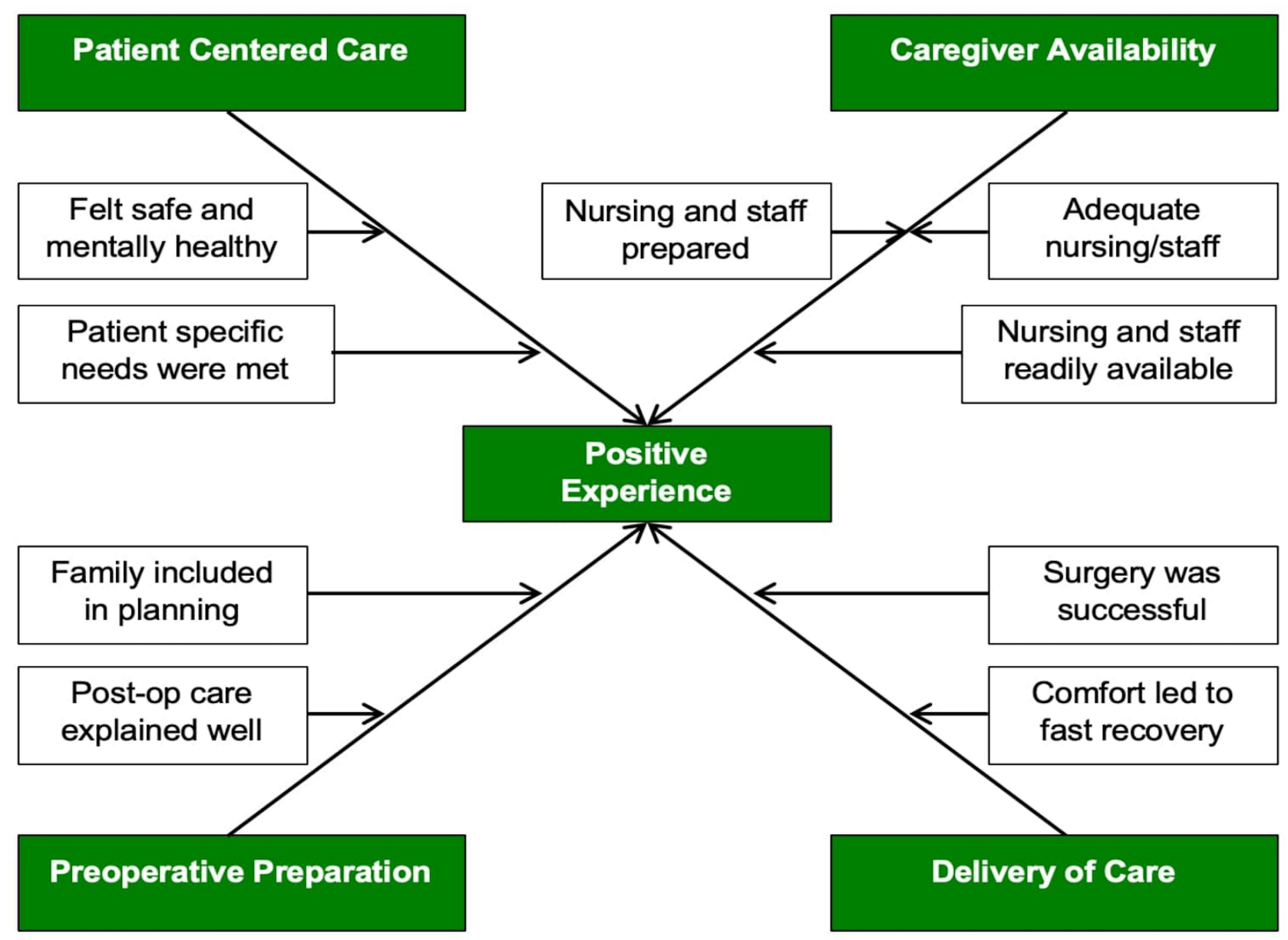

Figure 3 Box-and-arrow diagram of factors contributing to a POSITIVE patient experience. White boxes contain specific answers to the open-ended survey questions. Through qualitative coding these answers were classified under four broad themes, as shown in the green shaded boxes. 


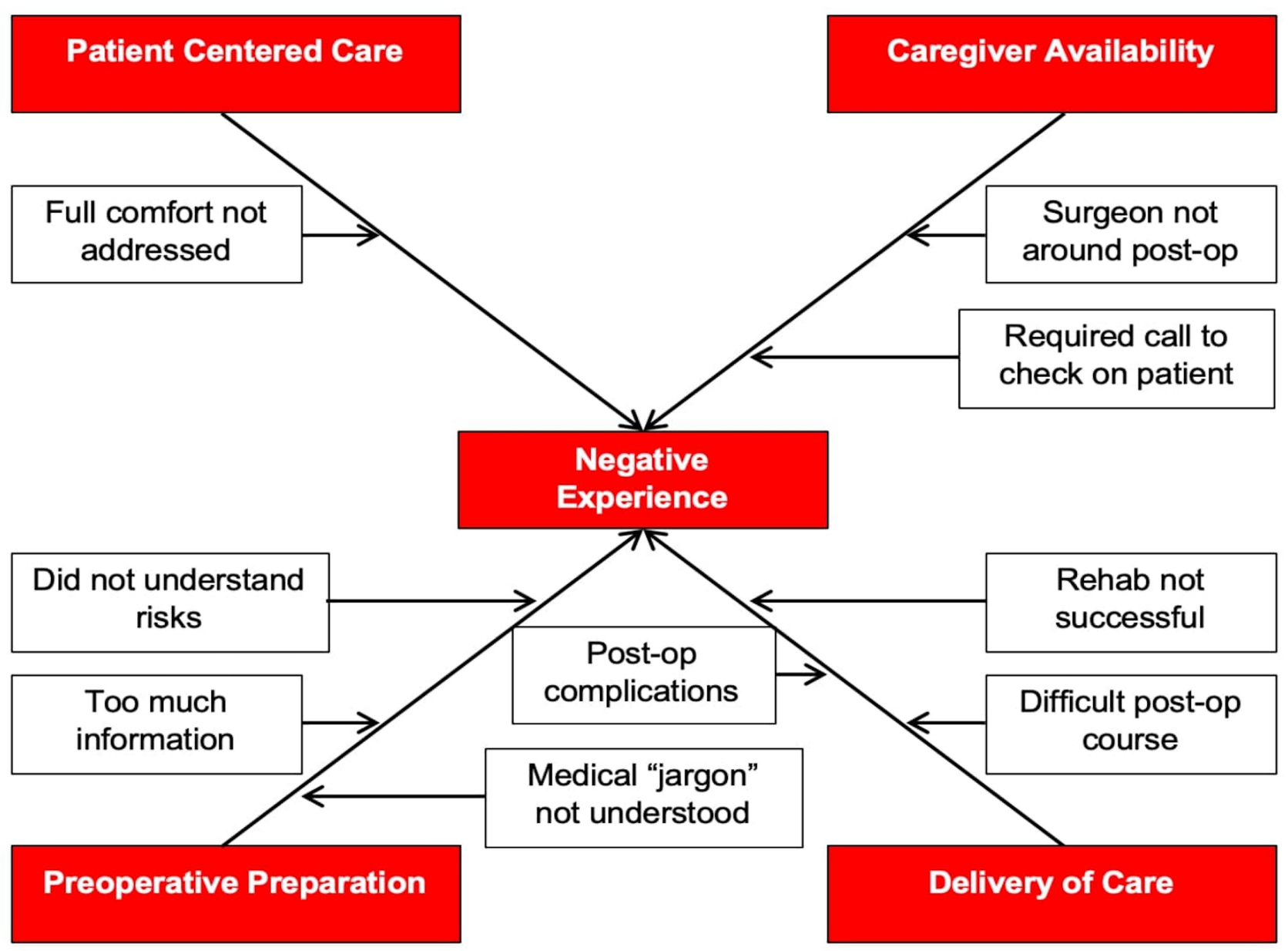

Figure 4 Box-and-arrow diagram of factors contributing to a NEGATIVE patient experience. Although the specific answers in the white boxes are different than those in Figure 3, through qualitative coding they were assigned into the same four themes as before, this time shown in the red shaded boxes.

However, we argue it is too simplified to use a single word description to establish patient satisfaction. It also fails to identify areas where improvement can be made.

Instead, we identified specific factors that contribute to positive and negative patient experiences with RC. The majority of our analysis involved two qualitative, openended questions. These questions allowed patients to explain in their own words what specifically led to a positive or negative experience. With qualitative coding, we were able to create four themes under which the individual responses fell. After being assigned to a theme, the responses were then separated into positive and negative contributors to patient experience (Figures 3 and 4).

As mentioned previously, we were most interested in preoperative education and its contribution to patient satisfaction. Daneshmand argues in a review article evaluating satisfaction in RC patients after orthotopic urinary diversion that thorough preoperative counseling with realistic expectations can ensure optimal outcomes and patient satisfaction. ${ }^{20}$ Another article from Saika et al demonstrated that excessive preoperative expectation might lower postoperative patient satisfaction in $\mathrm{RC}$ patients. ${ }^{12}$ Other studies from outside urological literature have found that information provided before the procedure is a strong predictor of patient satisfaction following surgery. ${ }^{21,22}$ From the two other quantitative questions in our study, $23.1 \%$ of patients in our study indicated they did not receive enough education preoperatively on surgical expectations, or how to care for themselves postoperatively. From the results of the qualitative questions (Figures 3 and 4), we identified specific aspects of preoperative preparation that contributed positively and negatively to patient experience, and have used this information to improve our preoperative patient and family education prior to RC. 
Another theme derived from the qualitative responses was the importance of effective delivery of care. Responses that fell under this theme included the operative outcome, hospital course and postoperative recovery. Although it may seem intuitive that a successful and uncomplicated operation would lead to a positive experience and therefore high patient satisfaction, the available literature is mixed. One study that reviewed patient experience after general anesthesia suggests any postoperative complication was strongly related with patient dissatisfaction. ${ }^{23}$ However, a more recent article examining Hospital Consumer Assessment of Healthcare Providers and Systems data found that with the exception of low mortality rate, favorable surgical outcomes were not associated with higher patient satisfaction. ${ }^{24}$ Regardless, we will use the responses coded under this theme to improve patient experience while in the hospital, as well as provide better preoperative education on postoperative expectations.

The final two themes attributing to patient experience identified in our study were caregiver availability and patient-centered care. The responses coded under these two themes tended to overlap. Patient-centered care uses the concept of shared decision-making to ensure the treatment plan accounts for the patient's desired outcomes as well as the physicians, and has been shown across multiple fields of medicine and surgery to improve patient satisfaction. ${ }^{25-27}$ In order to ensure care is patient centered, caregiver must be readily available. This includes surgeons, nurses and all members of the health-care team. Dugdale et al and Draeger et al suggest maximizing face-to-face time and time spent on shared decision-making increases patient satisfaction. ${ }^{28,29}$ Although these studies refer primarily to the outpatient setting, the concept should also be employed in a postoperative hospital setting. Similar evidence exists in the nursing literature that frequency of visits and caring behaviors improved patient satisfaction. ${ }^{30}$

This study has several limitations that we must recognize. With only 13 participants, it is small in overall population but does represent $52 \%$ (13 of 25) of the target population. As with most survey studies, patients who elected to participate may have different perspectives than the patient population as a whole. Also, the decision to include quantitative questions specifically addressing preoperative education and expectations may have affected participant responses to the open-ended questions.

Despite these limitations, the results of our qualitative survey study are very important to understanding what factors contribute to patient experience during $\mathrm{RC}$ at our institution. Although the results to the quantitative questions could be interpreted as high overall patient satisfaction $(92.3 \%$ of patients reporting good or excellent care), we do not feel this fully illustrates patient experience. Based on the analysis of the qualitative open-ended questions, there are still many areas where improvement is needed. This is especially true in the area of preoperative preparation, as corroborated by responses to the other quantitative questions from our survey (23.1\% of patients did not feel they received adequate preoperative education or instruction on how to care for themselves postoperatively). There are also areas where improvement can be made in delivery of care, care give availability and patient-centered care.

With the information from this study in mind, we will work to improve patient satisfaction with RC at our institution. Already within our recently implemented RC enhanced recovery protocol, we have changed patient and family preoperative education to include improved information on postoperative expectations, recovery and self-care. We also plan to repeat the survey in the future to identify additional trends and new areas in need of improvement.

\section{Conclusion}

Contributors to patient satisfaction are difficult to qualify, but important to understand in order to provide quality health care. Instead of relying on generic, quantitative questions to determine whether a patient is satisfied, it is helpful to identify specific areas that positively and negatively affect patient experience through qualitative questioning. By improving patient experience, we can continue to improve patient satisfaction with $\mathrm{RC}$ at our institution.

\section{Disclosure}

The authors declare no potential conflicts of interest with respect to the research, authorship, and/or publication of this article. The authors received no financial support for the research, authorship, and/or publication of this article.

\section{References}

1. Institute of Medicine (US) Committee on Quality of Health Care in America. Crossing the quality chasm: a new health system for the 21st century [internet]. Washington (DC): National Academies Press (US); 2001. Available from: http://www.ncbi.nlm.nih.gov/books/ NBK222274/. Accessed Aug 10, 2018.

2. Rosenthal GE, Shannon SE. The use of patient perceptions in the evaluation of health-care delivery systems. Med Care. 1997;35(11): NS58. doi:10.1097/00005650-199711001-00007

3. DuPree E, Anderson R, Nash IS. Improving quality in healthcare: start with the patient. Mt Sinai J Med J Transl Pers Med. 2011;78 (6):813-819. doi:10.1002/msj.20297 
4. Tsai TC, Orav EJ, Jha AK. Patient satisfaction and quality of surgical care in us hospitals. Ann Surg. 2015;261(1):2-8. doi:10.1097/ SLA.0000000000000765

5. Chang SS, Bochner BH, Chou R, et al. Treatment of non-metastatic muscle-invasive bladder cancer: AUA/ASCO/ASTRO/SUO Guideline. $J$ Urology. 1999;14(S1):S34-S40. doi:10.1016/j. juro.2017.04.086

6. Witjes JA, Lebret T, Compérat EM, et al. Updated 2016 EAU guidelines on muscle-invasive and metastatic bladder cancer. Eur Urol. 2017;71(3):462-475.

7. James AC, Izard JP, Holt SK, et al. Root causes and modifiability of 30-day hospital readmissions after radical cystectomy for bladder cancer. J Urol. 2016;195(4):894-899. doi:10.1016/j.juro.2015.10.175

8. Patel HD, Ball MW, Cohen JE, et al. Morbidity of urologic surgical procedures: an analysis of rates, risk factors, and outcomes. Urology. 2015;85(3):552-560. doi:10.1016/j.urology.2014.11.034

9. Quek ML, Stein JP, Daneshmand S, et al. A critical analysis of perioperative mortality from radical cystectomy. J Urol. 2006;175 (3):886-890. doi:10.1016/S0022-5347(05)00421-0

10. Jensen BT, Jensen JB, Laustsen S, et al. Multidisciplinary rehabilitation can impact on health-related quality of life outcome in radical cystectomy: secondary reported outcome of a randomized controlled trial. J Multidiscip Healthc. 2014;7:301-311.

11. Autorino R, Quarto G, Di Lorenzo G, et al. Health related quality of life after radical cystectomy: comparison of ileal conduit to continent orthotopic neobladder. Eur J Surg Oncol J Eur Soc Surg Oncol Br Assoc Surg Oncol. 2009;35(8):858-864.

12. Saika T, Arata R, Tsushima T, et al. Health-related quality of life after radical cystectomy for bladder cancer in elderly patients with an ileal conduit, ureterocutaneostomy, or orthotopic urinary reservoir: a comparative questionnaire survey. Acta Med Okayama. 2007;61 (4):199-203.

13. Sherwani Afak Y, Wazir BS, Hamid A, et al. Comparative study of various forms of urinary diversion after radical cystectomy in muscle invasive carcinoma urinary bladder. Int J Health Sci. 2009;3(1):3-11.

14. Rabow MW, Benner C, Shepard N, et al. Concurrent urologic and palliative care after cystectomy for treatment of muscle-invasive bladder cancer. Urol Oncol. 2015;33(6):267.e23-29. doi:10.1016/j. urolonc.2015.02.012

15. Benner C, Greenberg M, Shepard N, et al. The natural history of symptoms and distress in patients and families following cystectomy for treatment of muscle invasive bladder cancer. J Urol. 2014;191 (4):937-942. doi:10.1016/j.juro.2013.10.101

16. Gill L, White L. A critical review of patient satisfaction. Leadersh Health Serv. 2009;6(22):8-19. doi:10.1108/17511870910927994
17. Hekkert KD, Cihangir S, Kleefstra SM, et al. Patient satisfaction revisited: A multilevel approach. Soc Sci Med. 2009;69(1):68-75. doi:10.1016/j.socscimed.2009.04.016

18. Cerruto MA, D'Elia C, Cacciamani G, et al. Behavioural profile and human adaptation of survivors after radical cystectomy and ileal conduit. Health Qual Life Outcomes. 2014;7(12):46. doi:10.1186/ 1477-7525-12-46

19. Consuegra-Sánchez L, Martínez JA, Fernández Costa Á, et al. Measuring patient satisfaction in a cardiology service using associative maps. A new method. Rev Esp Cardiol Engl Ed. 2018.

20. Daneshmand S. Orthotopic urinary diversion. Curr Opin Urol. 2015;25(6):545-549. doi:10.1097/MOU.0000000000000226

21. Sørlie T, Sexton HC, Busund R, et al. Predictors of satisfaction with surgical treatment. Int J Qual Health Care. 2000;12(1):31-40. doi:10.1093/intqhe/12.1.31

22. Mira JJ, Tomás O, Virtudes-Pérez M, et al. Predictors of patient satisfaction in surgery. Surgery. 2009;145(5):536-541. doi:10.1016/ j.surg.2009.01.012

23. Myles PS, Williams DL, Hendrata M, et al. Patient satisfaction after anaesthesia and surgery: results of a prospective survey of 10,811 patients. Br J Anaesth. 2000;84(1):6-10.

24. Kennedy GD, Tevis SE, Kent KC. Is there a relationship between patient satisfaction and favorable outcomes? Ann Surg. 2014;260(4):592-8; discussion 598-600. doi:10.1097/SLA.0000000000000932

25. Fossa AJ, Bell SK, DesRoches C. OpenNotes and shared decision making: a growing practice in clinical transparency and how it can support patient-centered care. $J$ Am Med Inform Assoc JAMIA. 2018;29.

26. Pessaux P, Faucher V, Cuny R, et al. One-day diagnosis for hepatobiliary and pancreatic lesions: an innovative patient-centered care pathway organization. J Visc Surg. 2018;23.

27. Ikeda AK, Hong P, Ishman SL, et al. Evidence-based medicine in otolaryngology, part 8: shared decision making-impact, incentives, and instruments. Otolaryngol-Head Neck Surg off J Am Acad Otolaryngol-Head Neck Surg. 2018;159(1):11-16. doi:10.1177/ 0194599818763600

28. Dugdale DC, Epstein R, Pantilat SZ. Time and the patient-physician relationship. J Gen Intern Med. 1999;14(Suppl 1):S34-40. doi:10.1046/j.1525-1497.1999.00263.x

29. Draeger RW, Stern PJ. Patient-centered care in medicine and surgery. Hand Clin. 2014;30(3):353-359. doi:10.1016/j.hcl.2014.04.006

30. Palese A, Tomietto M, Suhonen R, et al. Surgical patient satisfaction as an outcome of nurses' caring behaviors: a descriptive and correlational study in six european countries. J Nurs Scholarsh. 2011;43 (4):341-350. doi:10.1111/j.1547-5069.2011.01413.x
Research and Reports in Urology

\section{Publish your work in this journal}

Research and Reports in Urology is an international, peer-reviewed, open access journal publishing original research, reports, editorials, reviews and commentaries on all aspects of adult and pediatric urology in the clinic and laboratory including the following topics: Pathology, pathophysiology of urological disease; Investigation and treatment of urological disease; Pharmacology of drugs used for the treatment of urological disease. The manuscript management system is completely online and includes a very quick and fair peer-review system, which is all easy to use. Visit http://www.dovepress.com/ testimonials.php to read real quotes from published authors. 